\title{
EFEITO DO MANEJO CULTURAL E QUÍMICONA INCIDÊNCIA E SEVERIDADE DA MANCHA-PRETA DOS CITROS ${ }^{1}$
}

\author{
ELIANA MAYRA TORRECILLAS SCALOPPI ${ }^{2}$, RONILDA LANA AGUIAR ${ }^{2}$, \\ ANTONIO DE GOES², MARCEL BELLATO SPÓSITO³
}

\begin{abstract}
RESUMO - A citricultura apresenta vários problemas fitossanitários, dentre os quais a mancha-preta dos citros (Guignardia citricarpa). O controle desta doença baseia-se no emprego de práticas culturais e no uso de fungicidas. Avaliou-se o efeito do manejo do mato em conjunto com o químico no controle da doença. Os experimentos foram instalados em pomares de laranjeiras-doces, nos municípios de Matão, Rio Claro e Mogi Guaçu, no Estado de São Paulo. No manejo do mato, comparou-se o uso isolado de roçadeira ecológica com o conjugado rastelo mecânico e trincha, aos 35 dias, após $2 / 3$ de pétalas caídas. No controle químico, foram realizadas duas pulverizações com fungicida protetor e de 2 a 5 pulverizações da mistura de produto sistêmico com protetor, aos 45 dias, após $2 / 3$ de pétalas caídas, em intervalos de aplicação de 35 dias. Em todas as aplicações, foi adicionado óleo mineral emulsionável $(0,25 \%)$. Avaliou-se a área abaixo da curva de progresso da incidência e severidade da doença, com os dados de cinco avaliações realizadas quinzenalmente, a partir da maturidade fisiológica dos frutos. Em todas as áreas, o uso do controle químico, associado com o manejo do mato, reduziu a intensidade da doença.
\end{abstract}

Termo para indexação: Citrus spp., Guignardia citricarpa, fungicidas.

\section{EFFECT OF CULTURAL AND CHEMICAL MANAGEMENT IN THE INCIDENCE AND SEVERITY OF CITRUS BLACK SPOT}

\begin{abstract}
The citrus plants has several phytosanitary problems, including citrus black spot (Guignardia citricarpa). Control of this disease is based on cultural practices and application of fungicides. The effect of the weed management and chemical control was evaluated. The experiments were carried out in sweet orange orchards in Matão, Rio Claro and Mogi Guaçu municipalities in the state of São Paulo, Brazil. In the experiment of weed management, the use of ecological brushcutter was compared with the use of mechanical rake and brush combined, at 35 days after $2 / 3$ of petals fallen. Chemical control was carried out by two spraying of protective fungicide and from 2 to 5 spraying of systemic and protective fungicides 45 days after $2 / 3$ of petals fallen. The range of these spraying was 35 days and in all of them emulsifiable mineral oil $(0.25 \%)$ was added. The area under the curve of the incidence progress and severity of the disease was evaluated using data from five evaluations that were realized every 15 days from the physiological maturity of the fruits. The use of chemical control associated with weed management decreased the intensity of the disease in all areas evaluated.
\end{abstract}

Index terms: Citrus spp., Guignardia citricarpa, fungicides.

${ }^{1}$ (Trabalho 021-11). Recebido em: 04-01-2011. Aceito para publicação em: 19-01-2012. Parte da Tese de Doutorado da primeira autora.

${ }^{2}$ Departamento de Fitossanidade, UNESP/FCAV, Campus de Jaboticabal, Via de Acesso Prof. Paulo Donato Castellane, s/n, CEP 14890-900, Jaboticabal-SP. emts@fcav.unesp.br; ronildaaguiar@yahoo.com.br; agoes@fcav.unesp.br

${ }^{3}$ Departamento de Produção Vegetal, USP/ESALQ, Av. Pádua Dias, 11, CEP 13418-900, Piracicaba-SP. mbsposito@usp.br 


\section{INTRODUÇÃO}

A mancha-preta dos citros (MPC), causada pelo fungo Guignardia citricarpa (Phyllosticta citricarpa McAlp. Van der Aa), produz lesões na casca dos frutos, depreciando-os comercialmente para o mercado interno de frutas frescas e restringindo sua exportação (AGUILAR-VILDOSO et al., 2002). Em áreas com alta intensidade da MPC, a doença pode causar queda prematura de frutos (CALAVAN, 1960; KLOTZ, 1978).

O patógeno produz dois tipos de inóculo, os ascósporos (esporos sexuais), formados em pseudotécios nas folhas caídas em decomposição e dispersos pela ação do vento, e os conídios (esporos assexuais), formados em picnídios nas lesões dos frutos e de folhas aderidas às plantas e em ramos secos, dispersos a curtas distâncias pela ação da água (McONIE, 1964; KOTZÉ, 1981).

Nas condições ambientais do Estado de São Paulo, onde o período de inverno é seco, ocorre queda acentuada de folhas cítricas, o que acarreta, no início do período chuvoso, na primavera, um aumento na produção e dispersão de ascósporos (AGUILARVILDOSO et al., 2002).

O controle da MPC baseia-se no emprego de práticas culturais e, principalmente, no uso de fungicidas. A prática cultural restringe-se ao uso de roçadeiras que apresentam as laterais abertas, conhecidas como roçadeiras ecológicas, cuja finalidade é roçar as entrelinhas de plantio e jogar o mato sob a copa das plantas. O mato roçado forma uma barreira física que impede a dispersão dos ascósporos, reduzindo as infecções em frutos (FEICHTENBERGER et al., 2005; ROSSÊTTO, 2009). Outros equipamentos vêm sendo testados no controle da MPC, como o uso do conjugado rastelo mecânico e trincha. $\mathrm{O}$ rastelo mecânico, composto por 30 hastes de borracha sintética, com tamanho variando de 24 a $32 \mathrm{~cm}$, tem por finalidade remover as folhas de citros em decomposição debaixo da copa das plantas, jogandoas para a entrelinha de plantio e a trincha, que é um picador rotativo de eixo horizontal, composta por quatro correias dentadas, e um rolo triturador com 20 martelos de $1,3 \mathrm{~kg}$ cada tem por finalidade triturar o material vegetal (VICON, 2010). O uso desses equipamentos tem como objetivo reduzir a fonte de inóculo da MPC, principalmente no final do inverno, período seco, antes do florescimento dos citros, já que, nessa época, a maioria dos pomares não tem uma quantidade de mato necessária para utilizar a roçadeira ecológica.

Na maioria dos pomares paulistas, o controle da MPC está alicerçado na pulverização sequencial de fungicidas (FEICHTENBERGER et al., 2005). São aplicados fungicidas protetores, principalmente os cúpricos, nas fases de pós-florescimento, seguido de pulverizações com a mistura em tanque de fungicidas protetores e sistêmicos, acrescidos de óleo mineral ou vegetal emulsionáveis (GOES et al., 1990; GOES; WIT, 1999; FEICHTENBERGER et al., 2000). O número de pulverizações, assim como os fungicidas utilizados dependem de uma série de fatores, incluindo o nível de inóculo na área, a variedade de copa, a idade e o tamanho das plantas, e o destino da produção (FEICHTENBERGER et al., 2005). Os frutos das variedades cítricas tardias, mesmo apresentando suscetibilidade semelhante às variedades precoces e de meia-estação (SPÓSITO et al., 2004a), exibem maior nível de incidência e severidade de sintomas causados por G. citricarpa. Isso decorre pelo fato de essas apresentarem maturação mais lenta, permanecendo mais tempo nas plantas, e expondo-se, naturalmente, à maior temperatura e luminosidade nos meses da primavera e verão (BRODRICK; RABIES, 1971).

Dadas as características biológicas do fungo G. citricarpa e a dinâmica da MPC, depreende-se a necessidade da adoção, de forma integrada, de medidas de controle com o objetivo de minimizar os danos causados pela doença. A adoção sistematizada e harmoniosa dessas medidas de controle visa a interromper ou a desacelerar o progresso da doença (KIMATI; BERGAMIN FILHO, 1996). O manejo integrado implica a utilização de todas as técnicas disponíveis dentro de um programa unificado, de tal modo a manter a população de organismos nocivos abaixo do limiar de dano econômico e a minimizar os efeitos colaterais prejudiciais ao ambiente (BERGAMIN FILHO; AMORIM, 1996). Dentro dessas medidas, o uso de práticas culturais, principalmente relacionadas à redução do inóculo, como os ascósporos formados nas folhas de citros em decomposição, tem sido fonte de estudos (BELLOTTE et al., 2009; ROSSÊTTO, 2009).

O presente trabalho teve como objetivo avaliar o efeito do manejo do mato associado ao uso de fungicidas no controle da mancha-preta dos citros.

\section{MATERIAL E MÉTODOS}

\section{Área experimental}

Foram conduzidos três experimentos, em pomares comerciais de laranjeiras-doces [Citrus sinensis (L.) Osbeck], na safra de 2008/2009, em diferentes municípios do Estado de São Paulo. Experimento 1 - no município de Matão, em pomar de laranjeira 'Natal', enxertada em citrumeleiro 'Swingle' (Citrus 
paradisi Macf. x Poncirus trifoliata L. Raf.), com 18 anos de idade, e plantado no espaçamento de $8 \times 5$ m. Experimento 2 - no município de Rio Claro, em pomar de laranjeira 'Natal', enxertada em limoeiro 'Cravo' (C. limonia Osbeck), com 18 anos de idade, e plantado no espaçamento de 7 x $5 \mathrm{~m}$. Experimento 3 - no município de Mogi Guaçu, em pomar de laranjeira 'Folha Murcha', enxertada em limoeiro 'Cravo', com 14 anos de idade, e plantado no espaçamento de $8 \times 3 \mathrm{~m}$. Todas as áreas experimentais possuíam histórico da MPC. Os tratamentos foram iguais nas três áreas experimentais.

\section{Delineamento experimental}

Os experimentos foram conduzidos no delineamento de blocos casualizados, em faixas, com duas repetições. Os tratamentos foram constituídos pela combinação de cinco tratamentos com fungicidas e dois com o manejo do mato.

Cada parcela experimental foi constituída de 16 plantas na linha de plantio, sendo as quatro plantas centrais utilizadas nas avaliações. Entre os blocos, manteve-se uma linha de bordadura, para minimizar a contaminação das parcelas vizinhas devido à deriva dos fungicidas durante as pulverizações.

\section{Controle químico}

Todas as parcelas foram tratadas com duas aplicações de fungicida protetor, oxicloreto de cobre (Kocide $\mathrm{WDG}^{\circledR}$, Du Pont do Brasil S.A.) a 90g $\mathrm{Cu}^{++} / 100 \mathrm{~L}$ de $\mathrm{H}_{2} \mathrm{O}$, em mistura com óleo mineral emulsionável (Assist ${ }^{\circledR}$, Basf S.A.) a 0,25\%, após a queda de $2 / 3$ de pétalas e 28 dias após.

Aos 45 dias após a queda de $2 / 3$ de pétalas, iniciaram-se as aplicações com produtos sistêmicos, em mistura com oxicloreto de cobre e óleo mineral emulsionável $(0,25 \%)$, variando de duas a cinco pulverizações, aplicadas em intervalos de 35 dias. Os fungicidas azoxystrobin (Amistar ${ }^{\circledR}$, Syngenta Proteção de Cultivos Ltda.) a 3,75 g/100 L de $\mathrm{H}_{2} \mathrm{O}$ e tiofanato metílico $\left(\right.$ Cercobin $^{\circledR}$, Nippon Soda CO. Ltda.) a $50 \mathrm{~mL} / 100 \mathrm{~L}$ de $\mathrm{H}_{2} \mathrm{O}$ foram aplicados alternadamente.

Os tratamentos químicos utilizados foram: (i) duas aplicações de fungicida protetor (2P); (ii) 2P mais duas aplicações de fungicida sistêmico em mistura com fungicida protetor $(2 \mathrm{P}+2 \mathrm{SP})$; (iii) $2 \mathrm{P}$ mais três aplicações de fungicida sistêmico em mistura com fungicida protetor $(2 \mathrm{P}+3 \mathrm{SP})$; (iv) $2 \mathrm{P}$ mais quatro aplicações de fungicida sistêmico em mistura com fungicida protetor $(2 \mathrm{P}+4 \mathrm{SP})$; e (v) $2 \mathrm{P}$ mais cinco aplicações de fungicida sistêmico em mistura com fungicida protetor $(2 \mathrm{P}+5 \mathrm{SP})$.

As pulverizações foram realizadas com auxílio de pulverizador equipado com defletor de ar bilateral, empregando nos experimentos 1 e 3 pulverizador Jacto, modelo Arbus 2000, e no experimento 2, pulverizador Natali, modelo Alfa 4000. O conjunto trator-pulverizador foi calibrado para proporcionar uma velocidade de deslocamento de 3 a $5 \mathrm{~km} / \mathrm{h}$. Foram utilizadas pontas de pulverização AD3/AC31, com pressão de trabalho de 150 Libras/ $\mathrm{pol}^{2}$ e vazão de $1,63 \mathrm{~L} / \mathrm{min} /$ bico, produzindo um espectro de gotas com diâmetro mediano volumétrico entre 150 e $200 \mu \mathrm{m}$, proporcionando um volume de calda de 4,3; 5,6 e 3,4 L/planta nos experimentos 1 ; 2 e 3 , respectivamente.

\section{Manejo do mato}

Comparou-se o uso isolado da roçadeira ecológica com a roçadeira convencional mais o conjugado rastelo mecânico e trincha, aos 35 dias após o estádio de $2 / 3$ de pétalas caídas, no intuito de reduzir a quantidade de doença nos frutos. O rastelo mecânico foi acoplado na parte dianteira do trator, e a trincha, modelo TRL 2,2, com largura de trabalho de $2,20 \mathrm{~m}$, acoplada na traseira do trator. $\mathrm{O}$ equipamento conjugado foi calibrado para proporcionar uma velocidade de deslocamento de 2,4 $\mathrm{km} / \mathrm{h}$, removendo com o rastelo mecânico as folhas de citros em decomposição de baixo da copa das plantas para a entrelinha, para serem trituradas pela trincha. Durante toda a condução dos experimentos, as demais roçadas foram feitas exclusivamente com roçadeira ecológica em todas as parcelas das áreas experimentais

\section{Avaliações e análise dos dados}

Avaliaram-se a incidência (porcentagem de frutos sintomáticos) e a severidade (porcentagem da casca lesionada) da MPC em 25 frutos ao acaso, de cada planta da área útil, em cinco períodos, a intervalos de quinze dias. As avaliações iniciaram-se 315 dias após o estádio de $2 / 3$ de pétalas caídas, quando os frutos já estavam fisiologicamente maduros (sólidos solúveis/acidez titulável total próximo a 8). Para a avaliação da severidade da doença, foi utilizada escala diagramática (SPÓSITO et al., 2004b). Tanto para a incidência quanto para a severidade da MPC, foi calculada a área abaixo da curva de progresso da doença (AACPD), e os dados foram analisados pelo teste de comparação de médias de Tukey $(0,5 \%)$, utilizando o programa AgroEstat versão 1.0 (BARBOSA; MALDONATO JÚNIOR, 2010).

\section{RESULTADOS E DISCUSSÃO}

No município de Matão, em pomar de laranjeira 'Natal' enxertada em citrumeleiro 'Swingle', as áreas abaixo da curva de progresso da incidência da MPC, independentemente do número de pulveriza- 
ções, do uso de roçadeira ecológica ou do conjugado rastelo mecânico e trincha, 35 dias após o estádio de $2 / 3$ de pétalas caídas, não apresentaram diferenças significativas (Tabela 1). Entretanto, dentro de cada sistema de manejo do mato, o tratamento químico $2 \mathrm{P}$ $+5 \mathrm{SP}$ apresentou menores valores de incidência da doença durante o período avaliado. Os tratamentos $2 \mathrm{P}+2 \mathrm{SP}$ e $2 \mathrm{P}+3 \mathrm{SP}$ não diferiram significativamente do tratamento com duas aplicações de cobre mais óleo emulsionável (2P) (Tabela 1).

Para a área abaixo da curva de progresso da severidade da MPC, não houve interação entre o manejo do mato e o controle químico. No manejo do mato, o conjugado rastelo mecânico e trincha reduziu a severidade da doença durante o período avaliado, quando comparado com a roçadeira ecológica (Tabela 2). Em relação ao controle químico, no tratamento $2 \mathrm{P}+5 \mathrm{SP}$, ocorreu a menor severidade (Tabela 3).

O uso do conjugado rastelo mecânico e trincha, portanto, reduziu a severidade dos sintomas nos frutos, mas não o número de frutos sintomáticos. Nessa situação, o controle químico $2 \mathrm{P}+5 \mathrm{SP}$ diminuiu pela metade a incidência da MPC no período avaliado e em aproximadamente quatro vezes a severidade, quando comparado com apenas duas aplicações de protetor mais óleo mineral (2P).

No município de Rio Claro, em pomar de laranjeira 'Natal' enxertada em limoeiro 'Cravo', na área abaixo da curva de progresso da incidência da MPC, constatou-se um efeito positivo do uso do conjugado rastelo mecânico e trincha quando comparado com a roçadeira ecológica, somente nos tratamentos pulverizados com $2 \mathrm{P}+4 \mathrm{SP}$ ou $2 \mathrm{P}$ $+5 \mathrm{SP}$, reduzindo a incidência da doença no período avaliado (Tabela 4). Quanto ao controle químico, o tratamento $2 \mathrm{P}+5 \mathrm{SP}$ diferiu significativamente dos demais tratamentos, no manejo com o conjugado rastelo mecânico e trincha, não diferindo significativamente de $2 \mathrm{P}+4 \mathrm{SP}$, no manejo com a roçadeira ecológica (Tabela 4).

Em relação à área abaixo da curva de progresso da severidade da MPC, não houve interação entre manejo do mato e controle químico. Quanto ao manejo do mato, não houve diferenças entre o uso do conjugado rastelo mecânico e trincha com o uso de roçadeira ecológica. Para o controle químico, os melhores tratamentos foram $2 \mathrm{P}+4 \mathrm{SP}$ e $2 \mathrm{P}+5 \mathrm{SP}$, não diferindo estatisticamente entre si (Tabela 5).

A redução de uma aplicação de sistêmico mais protetor e óleo, de $2 \mathrm{P}+5 \mathrm{SP}$ para $2 \mathrm{P}+4 \mathrm{SP}$, quando manejado em conjunto com roçadeira ecológica, proporcionou o mesmo controle da doença, tanto para a quantidade de frutos sintomáticos no pe- ríodo avaliado quanto para a severidade dos sintomas nos frutos. Entretanto, houve um efeito positivo entre o uso do rastelo mecânico e trincha com o tratamento químico $2 \mathrm{P}+5 \mathrm{SP}$, reduzindo pela metade a incidência da doença durante o período de avaliação.

No município de Mogi Guaçu, em pomar de laranjeira 'Folha Murcha', enxertada sobre limoeiro 'Cravo', na área abaixo da curva de progresso da incidência da MPC, verificou-se um efeito positivo do uso do conjugado rastelo mecânico e trincha quando comparado com a roçadeira ecológica, somente nos tratamentos pulverizados com $2 \mathrm{P}+4 \mathrm{SP}$ ou $2 \mathrm{P}+5 \mathrm{SP}$, reduzindo a incidência da doença no período avaliado (Tabela 6). Quanto ao controle químico, o tratamento $2 \mathrm{P}+5 \mathrm{SP}$ diferiu significativamente dos demais tratamentos, nos dois sistemas de manejos do mato utilizados (Tabela 6).

Para a área abaixo da curva de progresso da severidade da MPC, detectou-se uma diferença no manejo do mato somente no tratamento químico $2 \mathrm{P}$, onde o uso do conjugado rastelo mecânico e trincha apresentou menor severidade durante o período de avaliação quando comparado com o uso da roçadeira ecológica. Quanto ao controle químico, independentemente do manejo do mato utilizado, $2 \mathrm{P}+4 \mathrm{SP}$ e $2 \mathrm{P}$ + 5SP foram os que apresentaram menores valores para a severidade (Tabela 7).

Verificou-se um efeito positivo resultante do uso do manejo do mato associado ao controle químico, apresentando os menores valores de incidência da MPC no período avaliado com o uso do rastelo mecânico e trincha, em $2 \mathrm{P}+5 \mathrm{SP}$, com consequente redução dos níveis de sintomas, quando comparado com o controle químico 2P. Para a severidade, apenas com o controle químico, conseguiu-se reduzir a MPC. Os tratamentos $2 \mathrm{P}+4 \mathrm{SP}$ e $2 \mathrm{P}+5 \mathrm{SP}$ reduziram 3,5 vezes a quantidade de sintomas durante o período avaliado quando comparado com $2 \mathrm{P}$.

De acordo com os dados obtidos, tanto para a incidência quanto para a severidade de sintomas de MPC, verificou-se que o aumento do número de pulverizações redundou em menor intensidade da doença, independentemente do manejo adotado. Quanto ao manejo do mato, foi observado que o uso do conjugado rastelo mecânico e trincha, nas três áreas experimentais, contribuiu para a redução da incidência de sintomas da MPC, especialmente nas áreas onde naturalmente há maior intensidade da doença (Rio Claro e Mogi Guaçu), somente quando as plantas foram tratadas com seis ou sete pulverizações de fungicidas. Já a severidade da MPC foi reduzida apenas em Matão, onde a intensidade da doença foi menor.

Em áreas onde o patógeno se encontra estabelecido há mais tempo, como em Rio Claro e Mogi 
Guaçu, a contribuição dos conídios ao incremento da doença tem maior importância do que os ascósporos, que são importantes no início da epidemia por aumentar o número de plantas com a doença (SPÓSITO et al., 2008). Portanto, nesses municípios, ao se aplicar de 6 a 7 vezes o fungicida, reduziu-se a intensidade da doença, fazendo com que fosse observada a contribuição adicional do conjugado rastelo mecânico e trincha na redução do número de ascósporos e, portanto, a redução da incidência da doença em frutos cítricos. $\mathrm{Na}$ área de Matão, onde a doença apresenta menor intensidade, pode-se observar maior contribuição do conjugado rastelo mecânico e trincha na redução da severidade da doença, isso provavelmente porque os ascósporos ainda nessa área apresentam um papel fundamental para o incremento da doença.

Em todas as áreas experimentais, o uso do conjugado rastelo mecânico e trincha, com a roçadeira convencional, aos 35 dias após $2 / 3$ da queda de pétalas dos citros, seguido do uso sequencial de roçadeira ecológica, associado a 7 pulverizações de fungicidas, foi o tratamento que mais contribuiu para a redução da doença, expresso em termos de valores da curva de progresso da incidência da MPC. Portanto, o manejo do mato, em conjunto com o controle químico são de grande importância para a redução da intensidade de sintomas da mancha-preta em pomares cítricos.

TABELA 1 - Área abaixo da curva de progresso da incidência da mancha-preta dos citros (Guignardia citricarpa), avaliada em frutos de laranjeira 'Natal', de pomar onde se utilizou para o controle da doença a associação manejo cultural e químico, na safra de 2008/2009, no município de Matão-SP.

\begin{tabular}{ccc}
\hline \multirow{2}{*}{ Controle químico } & \multicolumn{3}{c}{ Manejo do mato } \\
\cline { 2 - 3 } & Roçadeira ecológica & Rastelo mecânico e trincha \\
\hline 2P & $7050,0 \mathrm{a}$ A & $7050,0 \mathrm{a}$ A \\
$2 \mathrm{P}+2 \mathrm{SP}$ & $7039,5 \mathrm{a}$ A & $7050,0 \mathrm{a}$ A \\
$2 \mathrm{P}+3 \mathrm{SP}$ & $6925,5 \mathrm{a}$ A & $6886,5 \mathrm{a}$ A \\
$2 \mathrm{P}+4 \mathrm{SP}$ & $5746,5 \mathrm{~b} \mathrm{~A}$ & $5533,5 \mathrm{~b} \mathrm{~A}$ \\
$2 \mathrm{P}+5 \mathrm{SP}$ & $3792,0 \mathrm{c} \mathrm{A}$ & $3789,0 \mathrm{c} \mathrm{A}$ \\
\hline
\end{tabular}

Médias seguidas por letras iguais, minúsculas nas colunas, não diferem entre si, pelo teste de Tukey, ao nível de 5\% de probabilidade. P: fungicida protetor (oxicloreto de cobre $90 \mathrm{~g} / 100 \mathrm{~L}$ de $\mathrm{H}_{2} \mathrm{O}$ ) aplicado em intervalos de 28 dias.

$\mathrm{S}$ : fungicida sistêmico (azoxystrobin e tiofanato metílico) aplicados alternadamente em intervalos de 35 dias.

TABELA 2 - Área abaixo da curva de progresso da severidade da mancha-preta dos citros (Guignardia citricarpa), avaliada em frutos de laranjeira 'Natal', na safra de 2008/2009, no município de Matão-SP.

\begin{tabular}{cc}
\hline Manejo do mato & AACPD \\
\hline Roçadeira ecológica & $95,5 \mathrm{a}$ \\
Rastelo mecânico e trincha & $84,7 \mathrm{~b}$ \\
\hline
\end{tabular}

Médias seguidas por letras iguais, minúsculas nas colunas e maiúsculas nas linhas, não diferem entre si, pelo teste de Tukey, ao nível de $5 \%$ de probabilidade.

TABELA 3 - Área abaixo da curva de progresso da severidade da mancha-preta dos citros (Guignardia citricarpa), em frutos de laranjeira 'Natal', sob diferentes manejos químicos, na safra de 2008/2009, no município de Matão-SP.

\begin{tabular}{cr}
\hline Controle químico & \multicolumn{1}{c}{ AACPD } \\
\hline $2 \mathrm{P}$ & $181,6 \mathrm{a}$ \\
$2 \mathrm{P}+2 \mathrm{SP}$ & $87,6 \quad \mathrm{~b}$ \\
$2 \mathrm{P}+3 \mathrm{SP}$ & $83,7 \quad \mathrm{~b}$ \\
$2 \mathrm{P}+4 \mathrm{SP}$ & $54,1 \quad \mathrm{c}$ \\
$2 \mathrm{P}+5 \mathrm{SP}$ & $43,5 \quad \mathrm{~d}$ \\
\hline
\end{tabular}

Médias seguidas por letras iguais não diferem entre si, pelo teste de Tukey, ao nível de $5 \%$ de probabilidade. P: fungicida protetor (oxicloreto de cobre $90 \mathrm{~g} / 100 \mathrm{~L}$ de $\mathrm{H}_{2} \mathrm{O}$ ) aplicado em intervalos de 28 dias.

$\mathrm{S}$ : fungicida sistêmico (azoxystrobin e tiofanato metílico) aplicado alternadamente em intervalos de 35 dias. 
TABELA 4 - Área abaixo da curva de progresso da incidência da mancha-preta dos citros (Guignardia citricarpa), avaliada em frutos de laranjeira 'Natal', de pomar onde se utilizou para o controle da doença a associação manejo cultural e químico, na safra de 2008/2009, no município de Rio Claro-SP.

\begin{tabular}{cccc}
\hline \multirow{2}{*}{ Controle químico } & \multicolumn{4}{c}{ Manejo do mato } \\
\cline { 2 - 5 } Roçadeira ecológica & Rastelo mecânico e trincha \\
\hline 2P & $8400,0 \mathrm{a} \quad \mathrm{A}$ & $8400,0 \mathrm{a}$ & $\mathrm{A}$ \\
$2 \mathrm{P}+3 \mathrm{SP}$ & $8321,5 \mathrm{a}$ A & $7822,5 \mathrm{ab}$ & $\mathrm{A}$ \\
$2 \mathrm{P}+4 \mathrm{SP}$ & $7711,0 \mathrm{ab} \mathrm{A}$ & $7151,0 \mathrm{~b}$ & $\mathrm{~A}$ \\
$2 \mathrm{P}+5 \mathrm{SP}$ & 6776,5 bc A & $5344,0 \mathrm{c}$ & $\mathrm{B}$ \\
\hline
\end{tabular}

Médias seguidas por letras iguais, minúsculas nas colunas e maiúsculas nas linhas, não diferem entre si, pelo teste de Tukey, ao nível de $5 \%$ de probabilidade.P: fungicida protetor (oxicloreto de cobre $90 \mathrm{~g} / 100 \mathrm{~L}$ de $\mathrm{H}_{2} \mathrm{O}$ ) aplicado em intervalos de 28 dias.

S: fungicida sistêmico (azoxystrobin e tiofanato metílico) aplicado alternadamente em intervalos de 35 dias.

TABELA 5 - Área abaixo da curva de progresso da severidade da mancha-preta dos citros (Guignardia citricarpa), em frutos de laranjeira 'Natal', sob diferentes manejos químicos, na safra de 2008/2009, no município de Rio Claro-SP.

\begin{tabular}{cc}
\hline Controle químico & AACPD \\
\hline $2 \mathrm{P}$ & $255,8 \mathrm{a}$ \\
$2 \mathrm{P}+2 \mathrm{SP}$ & $92,4 \mathrm{~b}$ \\
$2 \mathrm{P}+3 \mathrm{SP}$ & $77,6 \mathrm{bc}$ \\
$2 \mathrm{P}+4 \mathrm{SP}$ & $55,2 \mathrm{~cd}$ \\
$2 \mathrm{P}+5 \mathrm{SP}$ & $47,2 \mathrm{~d}$ \\
\hline
\end{tabular}

Médias seguidas por letras iguais não diferem entre si, pelo teste de Tukey, ao nível de $5 \%$ de probabilidade.

P: fungicida protetor (oxicloreto de cobre $90 \mathrm{~g} / 100 \mathrm{~L}$ de $\mathrm{H}_{2} \mathrm{O}$ ) aplicado em intervalos de 28 dias.S: fungicida sistêmico (azoxystrobin e tiofanato metílico) aplicado alternadamente em intervalos de 35 dias.

TABELA 6 - Área abaixo da curva de progresso da incidência da mancha-preta dos citros (Guignardia citricarpa), avaliada em frutos de laranjeira 'Folha Murcha', de pomar onde se utilizou para o controle da doença a associação manejo cultural e químico, na safra de 2008/2009, no município de Mogi Guaçu-SP.

\begin{tabular}{|c|c|c|}
\hline \multirow{2}{*}{ Controle químico } & \multicolumn{2}{|c|}{ Manejo do mato } \\
\hline & Roçadeira ecológica & Rastelo mecânico e trincha \\
\hline $2 \mathrm{P}$ & 10650,0 a $\mathrm{A}$ & 10650,0 a $A$ \\
\hline $2 \mathrm{P}+2 \mathrm{SP}$ & $10484,5 \mathrm{a} \quad \mathrm{A}$ & 10607,0 a \\
\hline $2 \mathrm{P}+3 \mathrm{SP}$ & $10159,0 \mathrm{a} \quad \mathrm{A}$ & $10373,0 \mathrm{a}$ \\
\hline $2 \mathrm{P}+4 \mathrm{SP}$ & 8093,5 b A & $6843,0 \mathrm{~b}$ \\
\hline $2 \mathrm{P}+5 \mathrm{SP}$ & $6272,0 \quad$ c A & 5052,5 c $\quad$ B \\
\hline
\end{tabular}

Médias seguidas por letras iguais, minúsculas nas colunas e maiúsculas nas linhas, não diferem entre si, pelo teste de Tukey, ao nível de $5 \%$ de probabilidade.

P: fungicida protetor (oxicloreto de cobre $90 \mathrm{~g} / 100 \mathrm{~L}$ de $\mathrm{H}_{2} \mathrm{O}$ ) aplicado em intervalos de 28 dias.S: fungicida sistêmico (azoxystrobin e tiofanato metílico) aplicado alternadamente em intervalos de 35 dias.

TABELA 7 - Área abaixo da curva de progresso da severidade da mancha-preta dos citros (Guignardia citricarpa), avaliada em frutos de laranjeira 'Folha Murcha', de pomar onde se utilizou para o controle da doença a associação manejo cultural e químico, na safra de 2008/2009, no município de Mogi Guaçu-SP.

\begin{tabular}{|c|c|c|}
\hline \multirow{2}{*}{ Controle químico } & \multicolumn{2}{|c|}{ Manejo do mato } \\
\hline & Roçadeira ecológica & Rastelo mecânico e trincha \\
\hline $2 \mathrm{P}$ & $279,5 \mathrm{a} \quad \mathrm{A}$ & 223,0 a B \\
\hline $2 \mathrm{P}+2 \mathrm{SP}$ & 163,4 b A & $153,5 \mathrm{~b} \quad \mathrm{~A}$ \\
\hline $2 \mathrm{P}+3 \mathrm{SP}$ & 128,2 с A & 134,8 b A \\
\hline $2 \mathrm{P}+4 \mathrm{SP}$ & $89,2 \mathrm{dA}$ & 84,2 c A \\
\hline $2 \mathrm{P}+5 \mathrm{SP}$ & $69,8 \quad \mathrm{~d} \mathrm{~A}$ & 63,8 c A \\
\hline
\end{tabular}

Médias seguidas por letras iguais, minúsculas nas colunas e maiúsculas nas linhas, não diferem entre si, pelo teste de Tukey, ao nível de $5 \%$ de probabilidade.

P: fungicida protetor (oxicloreto de cobre $90 \mathrm{~g} / 100 \mathrm{~L}$ de $\mathrm{H}_{2} \mathrm{O}$ ) aplicado em intervalos de 28 dias.S: fungicida sistêmico (azoxystrobin e tiofanato metílico) aplicado alternadamente em intervalos de 35 dias. 


\section{REFERENCIAS}

AGUILAR-VILDOSO, C.I.; RIBEIRO, J.G.B.; FEICHTENBERGER, E.; GOES, A. de; SPÓSITO, M.B. Manual técnico de procedimentos da mancha-preta dos citros. Brasília: MAPA/DAS/ DDIV, 2002. 72p.

BARBOSA, J.C.; MALDONADO JR., W. AgroEstat: sistema para análises estatísticas de ensaios agronômicos. Versão 1.0. Jaboticabal: Departamento de Ciências Exatas, 2010.

BELLOTTE, J.A.M.; KUPPER, K.C.; RINALDO, D.; SOUZA, A. de; PEREIRA, F.D.; GOES, A. de. Acceleration of the decomposition of Sicilian lemon leaves as an auxiliary measure in the control of citrus black spot. Tropical Plant Pathology, Brasília, v. 34, n. 2, p. 71-76, 2009.

BERGAMIN FILHO, A.; AMORIM, L. Doenças de plantas tropicais: epidemiologia e controle econômico. São Paulo: Agronômica Ceres, 1996. v. 1, p. 229-234.

BRODRICK, H.T.; RABIES, C.J. Light and temperature effect on symptom development and sporulation of Guignardia ciricarpa Kiely, on Citrus sinensis (Linn.) Osbeck. Phytophylactica, Pretoria, v.2, p. 157-64, 1971.

CALAVAN, E.C. Black spot of citrus. The California Citrograph, Los Angeles, v. 46, n. 11, p. $21-24,1960$

FEICHTENBERGER, E.; BASSANEZI, R.B.; SPÓSITO, M.B.; BELASQUE, J. Doenças dos citros (Citrus spp.). In: KIMATI, H.; AMORIM, L.; REZENDE, J.A.M.; BERGAMIN FILHO, A.; CAMARGO, L.E.A. (Ed.). Manual de fitopatologia: doenças das plantas cultivadas. São Paulo: Agronômica Ceres, 2005. v. 2, p. 475-476.

FEICHTENBERGER, E.; SPÓSITO, M.B.; VIANNA, J.H.T. Tratamentos fungicidas no controle de mancha-preta (Guignardia citricarpa) em laranjeira 'Valência'. Summa Phytopathologica, Jaboticabal, v. 26, p. $118,2000$.

GOES, A. de; BARROS, J.C.S.M. de; PINHEIRO, J.E. Controle da pinta-preta dos frutos de tangerina 'Rio' (Citrus deliciosa) ocasionada por Phyllosticta citricarpa. Fitopatologia Brasileira, Brasília, v. 15, p. $73-75,1990$.
GOES, A. de; WIT, C.P. Efeito da combinação de diferentes fungicidas sistêmicos e protetores no controle da mancha-preta dos frutos cítricos causada por Guignardia citricarpa. Fitopatologia Brasileira, Jaboticabal, v. 34, p. 201-202, 1999.

KIMATI, H.; BERGAMIN FILHO, A. Princípios gerais de controle. In: BERGAMIN FILHO, A.; KIMATI, H.; AMORIM, L. (Ed.). Manual de fitopatologia: princípios e controle. São Paulo: Agronômica Ceres, 1996. v. 1, p. 693-716,

KLOTZ, L.J. Fungal, bacterial, and nonparasitic diseases and injuries originating in the seebed, nursery, and orchard. In: REUTHER, W.; CALAVAN, E.C.; CARMAN, G.E. (Ed.). The citrus industry Riverside, University of California, p. 1-66, 1978.

KOTZÉ, J.M. Epidemiology and control of citrus black spot in South Africa. Plant Disease, Saint Paul, v. 65 , p. $945-950,1981$.

McONIE, K.C. The latent occurrence in Citrus and other hosts of a Guignardia easily confused with $G$. citricarpa, the citrus black spot pathogen. Phytopathology, Saint Paul, v. 54, p. 40-43, 1964.

ROSSÊTTO, M.P. Resistência varietal e manejo da mancha-preta dos citros. 2009. 75f. Dissertação (Mestrado em Agricultura Tropical e Subtropical, Tecnologia de Produção Agrícola) - Instituto Agronômico de Campinas, Campinas, 2009.

SPÓSITO, M.B.; AMORIM, L.; BASSANEZI, R.B.; BERGAMIN FILHO, A.; HAU, B. Spatial pattern of black spot incidence within citrus trees related to disease severity and pathogen dispersal. Plant Pathology, London, v. 57, p. 103-108, 2008.

SPÓSITO, M.B.; AMORIM, L.; BELASQUE JÚNIOR, J.; BASSANEZI, R.B.; AQUINO, R. Elaboração e validação de escala diagramática para avaliação da severidade da mancha-preta em frutos cítricos. Fitopatologia Brasileira, Brasília, v. 29, n. 1, p. 81-85, 2004b.

SPÓSITO, M.B.; BASSANEZI, R.B.; AMORIM, L. Resistência à mancha-preta dos citros avaliada por curvas de progresso da doença. Fitopatologia Brasileira, Brasília, v. 29, n. 5, p. 532-537, 2004a.

VICON. Vicon máquinas agrícolas. Disponível em: $<$ http://www.vicon.com.br/pt/modelos $>$. Acesso em: 16 out. 2010 